\title{
Peptides as Asymmetric Catalysts for Aldol Reactions
}

\author{
Helma Wennemers
}

\begin{abstract}
The article summarizes our research devoted to the development of peptidic catalysts for aldol reactions. Using the combinatorial method of 'catalyst-substrate coimmobilization' the peptides H-Pro-Pro-Asp- $\mathrm{NH}_{2}$ and $\mathrm{H}$-Pro-D-Ala-D-Asp- $\mathrm{NH}_{2}$ were identified as highly active and selective catalysts for direct aldol reactions. The results demonstrate that the higher complexity of peptides in comparison to rigid small organocatalysts can be a good trade-off for higher activity.
\end{abstract}

Keywords: Aldol reaction · Asymmetric catalysis · Combinatorial chemistry · Peptides

\section{Introduction}

Aldol reactions are among the most important $\mathrm{C}-\mathrm{C}$ bond forming reactions. As a result, a lot of research has been devoted to the development of catalysts for aldol reactions and produced a multitude of different catalysts. ${ }^{[1]}$ Most of them belong to the classes of enzymes or man-made catalysts that are either based on a metal center or are purely organic. Regardless of the large difference in molecular weight, both classes furnished examples of remarkably efficient catalysts that are commonly used in organic synthesis. ${ }^{[1]}$ In recent years, organocatalysts such as proline and other secondary amines have become increasingly popular. ${ }^{[2]}$ For many substrates high enantioselectivities are achieved, however, often poor activities make the use of large amounts of catalysts necessary. We were intrigued by the question whether short-chain peptides may be useful alternatives to enzymes and catalysts of low molecular weight. ${ }^{[3]}$ Since peptides offer many sites for structural and functional diversification we felt that optimal catalysts can be generated. However, due to the many degrees of freedom of short-chain peptides, the purely rational design of efficient peptidic catalysts for aldol reactions has proven difficult. ${ }^{[3,4]}$ Combinatorial screening methods on the other hand allow for catalyst discovery even if the factors that govern catalysis are only poorly understood. ${ }^{[5]}$ We therefore started the project by developing the combinatorial screening method of 'catalyst-substrate coimmobilization' that allows for the identification of catalysts among the members of one-bead-one-compound libraries. ${ }^{[6]}$ This method then led to the discovery of the peptides H-Pro-Pro-Asp- $\mathrm{NH}_{2}$ (1) and $\mathrm{H}-$ Pro-D-Ala-D-Asp- $\mathrm{NH}_{2}$ (2) as highly active and selective catalysts for aldol reactions. ${ }^{[7]}$ These contributions from our group to the field of peptidic catalysts for aldol reactions are summarized in this article.

\section{Catalyst-Substrate Coimmobilization}

We chose split-and-mix synthesis as a tool to generate compound libraries since it allows for the generation of a large degree of molecular diversity by simple means. ${ }^{[8]}$ Within the resulting one-bead-one-compound libraries each library member is localized on different beads. Thus, for visualizing reactions mediated by a catalyst on a single bead, the development of screening methods is a considerable challenge. ${ }^{[5]}$ We tackled this challenge by developing the method of 'catalyst-substrate coimmobilization'.[6] This method is not limited to the identification of peptidic catalysts, but allows for catalyst discovery among the members of any compound library and is applicable for most bimolecular reactions. 'Catalyst-substrate coimmobilization' relies on the immobilization of one reaction partner $(\mathbf{A})$ together with each library member, the potential catalyst, on the same bead (Fig. 1). A second reaction partner $(\mathbf{B})$ is labeled with a marker, for example a dye, fluorophor or radiolabel. Incubation of the catalyst-substrate coimmobilized library with the marked reaction partner $\mathbf{B}$ results in covalent attachment of the marker on beads carrying compounds that are able to mediate the reaction between $\mathbf{A}$ and $\mathbf{B}$. These beads are readily identified with a low-power microscope.
*Correspondence: Prof. Dr. H. Wennemers Department of Chemistry

University of Basel

St. Johanns-Ring 19

$\mathrm{CH}-4056$ Basel

Tel.: +41-61-267-1146

Fax: +41-61-267-0976

E-Mail: Helma.Wennemers@unibas.ch

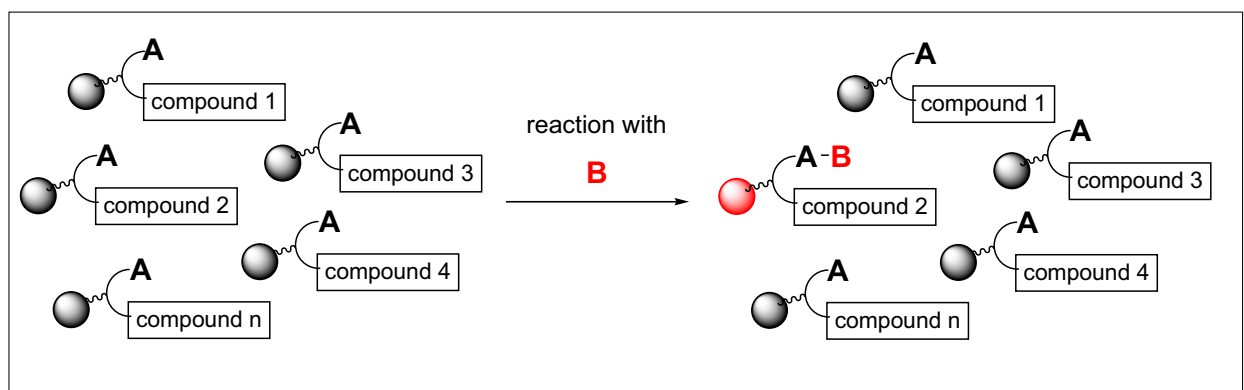

Fig. 1. 'Catalyst-substrate coimmobilization' 
The method was initially evaluated with a simple acylation reaction. ${ }^{[6]}$ These proofof-concept experiments demonstrated that cross-catalysis between different beads does not occur and that the identified hits are catalytically active when resynthesized and tested in solution phase. These initial trials also revealed that the length of the spacers between the bifunctional linker, reaction partner $\mathbf{A}$ and the potential catalysts plays a minor role. The only requirement is a sufficiently flexible linker to keep the risk of forced intramolecular reactions between reaction partner $\mathbf{A}$ and the potential catalyst on each bead at a minimum.

\section{Discovery of Peptidic Catalysts for Aldol Reactions Using Catalyst- Substrate Coimmobilization}

For the identification of catalytically active peptides for aldol reactions, we prepared a one-bead-one-compound tripeptide library at one end of a lysine-based bifunctional linker and attached a ketone derived from levulinic acid as reaction partner $\mathbf{A}$ at the other end (Fig. 2). ${ }^{[7,9]}$ Fifteen different $D-$ and L-amino acids were used in each position of the tripeptide library resulting in a molecular diversity of maximally $15^{3}=3375$ different tripeptides. The library was then allowed to react with the dye-marked benzaldehyde derivative 3 at room temperature for 1-2 $\mathrm{h}$. After extensive washings that removed any non-covalently bonded dyed compounds, only a few beads ( $\approx$ one out of 100 ) were colored bright red, indicating that the peptides on these beads had been able to mediate the aldol reaction between the resin bound ketone and the dyemarked benzaldehyde derivative.

Isolation and analysis of the peptides on several of the red beads revealed two main consensus sequences: H-Pro-Pro-Asp- $\mathrm{NH}_{2}$ (1) and H-Pro-D-Ala-D-Asp- $\mathrm{NH}_{2}$ (2). ${ }^{[7]}$ The same sequences emerged from screenings in which a benzaldehyde derivative was coimmobilized with the peptide library and a dye-marked levulinic acid was used, demonstrating that the roles of the two reaction partners can be reversed. ${ }^{[9]}$

Both selected peptides contain a secondary amine and a carboxylic acid, the same two functional groups present in proline. However, interestingly not all peptides with a secondary amine and a carboxylic acid were selected, suggesting that the ProPro and the Pro-D-Ala motives are important for catalysis.

\section{H-Pro-Pro-Asp- $\mathrm{NH}_{2}$ (1) and H-Pro-D-Ala-D-Asp- $\mathrm{NH}_{2}$ (2) as Catalysts for Aldol Reactions}

To evaluate the catalytic properties of H-Pro-Pro-Asp- $\mathrm{NH}_{2}$ (1) and H-Pro-D-Ala-

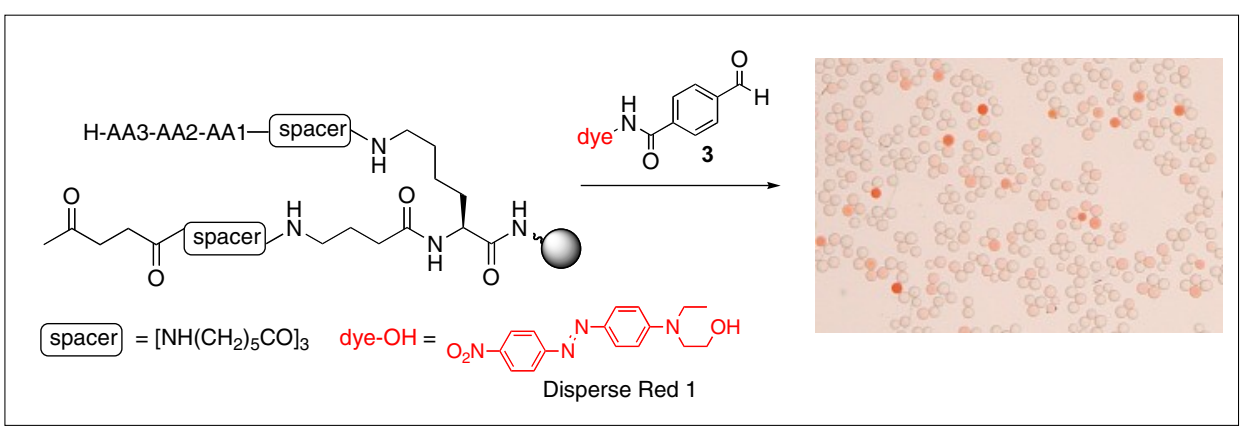

Fig. 2. Catalyst-substrate coimmobilization screening for peptidic aldol catalysts

Table. Aldol reactions catalyzed by peptides 1 and 2

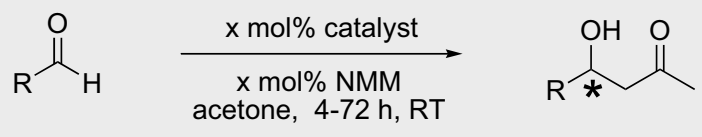

\begin{tabular}{|c|c|c|c|c|c|c|}
\hline entry $R$ & $\begin{array}{l}10 \mathrm{mo} \\
\mathrm{H}-\text { Pro } \\
\text { yield }\end{array}$ & $\begin{array}{l}\% \\
\text { Pro-Asp-NH } \\
\text { ee }\end{array}$ & $\begin{array}{l}1 \mathrm{~mol} \\
\mathrm{H}-\text { Pro } \\
\text { yield }^{\mathrm{a}}\end{array}$ & $\begin{array}{l}1 \\
\text {-Ala-D-Asp- } \mathrm{NH}_{2} \\
\text { ee }\end{array}$ & & $\mathrm{Pro}^{\mathrm{C}}$ \\
\hline $4-\mathrm{NO}_{2} \mathrm{Ph}$ & 73 & $70(R)$ & 99 & $80(S)$ & 68 & $76(R)$ \\
\hline $4-\mathrm{NO}_{2} \mathrm{Ph}$ & 53 & $81(R)$ & 98 & $90(S)$ & 30 & $71(R)$ \\
\hline $\mathrm{Ph}$ & 58 & $66(R)$ & 69 & $78(S)$ & 62 & $60(R)$ \\
\hline c-hex & 56 & $83(R)$ & 66 & $82(S)$ & 63 & $84(R)$ \\
\hline$i-\operatorname{Pr}$ & 75 & $91(R)$ & 79 & $79(S)$ & 97 & $96(R)$ \\
\hline neo-Pent & 24 & $70(S)$ & 28 & $73(R)$ & 22 & $36(S)$ \\
\hline
\end{tabular}

ayields are listed in \%, in entries 2, 3 and $530-70 \%$ of the aldehydes could be reisolated. bthe ee was determined by chiral stationary phase HPLC or GC analysis and is listed in \%, $(R)$ and $(S)$ indicate the absolute configuration of the aldol product. 'Data taken from B. List, R. A. Lerner, C. F. Barbas III, J. Am. Chem. Soc. 2000, 122, 2395. dReactions were performed at $-20^{\circ} \mathrm{C}$

D-Asp- $\mathrm{NH}_{2}$ (2), they were resynthesized and tested as catalysts in solution-phase aldol reactions between acetone and a range of different aldehydes. ${ }^{[7]}$ These studies revealed that both peptides are highly active and selective catalysts. $10 \mathrm{~mol} \%$ of 2 and only $1 \mathrm{~mol} \%$ of 1 are necessary to catalyze aldol reactions in good to excellent yields and high enantioselectivities (Table). In comparison, $30 \mathrm{~mol} \%$ of proline is required to obtain comparable yields and selectivities with typically longer reaction times. These results demonstrate that the higher complexity of the peptidic catalysts is a good trade-off for higher activity.

Furthermore, these experiments revealed that peptides $\mathbf{1}$ and $\mathbf{2}$ generate aldol products with opposite chirality despite the fact that both peptides have L-Pro at their $\mathrm{N}$-termini. This finding demonstrated that the selectivity of peptidic catalysts can be easily modified by simple modifications in their primary and thereby secondary structure.

To analyze the factors crucial for catalysis, we prepared a series of peptides related to $\mathbf{1}$ and $\mathbf{2}$ and tested their catalytic prop- erties. These experiments showed that the presence of the secondary amine and the carboxylic acid are crucial. For example, acetylation of the $\mathrm{N}$-terminal proline or replacement of the carboxylic acid with a sulfonic acid or an amide resulted in entire loss or strongly reduced reactivity. ${ }^{[7,10]}$ Furthermore, the relative orientation of these two functional groups towards each other proved important. Peptides containing a secondary amine and a carboxylic acid at other positions proved typically significantly less reactive and selective (e.g. H-Pro-Pro-OH, H-Pro-Pro-Glu-NH $\mathrm{N}_{2}$, H-Pro-D-Pro-Asp$\mathrm{NH}_{2}$ ), demonstrating the importance of the peptide conformation. ${ }^{[10]}$

Both the Pro-Pro and the Pro-D-Ala motives are known to induce turn conformations. This hypothesis is supported by molecular modeling studies using MacroModel 8.0 (OPLS force field). In the lowest energy structures, peptides 1 and $\mathbf{2}$ adopt preferentially turn conformation which bring the secondary amine and the carboxylic acid in close vicinity to each other (Fig. 3).

This conformational analysis also shed light on the reason for the opposing en- 


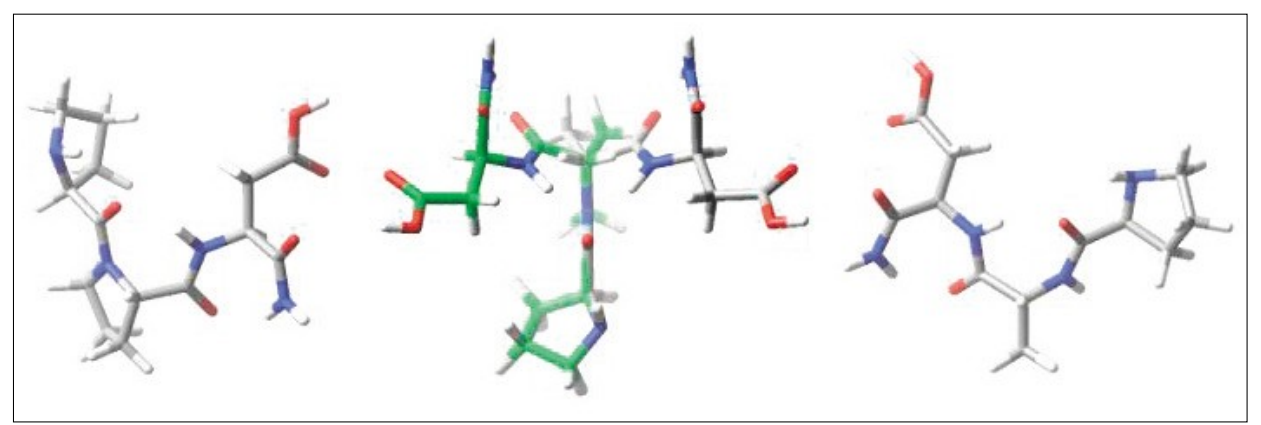

Fig. 3. Lowest energy conformations of H-Pro-Pro-Asp- $\mathrm{NH}_{2} \mathbf{1}$ (left), H-Pro-D-Ala-D-Asp- $\mathrm{NH}_{2} 2$ (right) and an overlay (middle) as calculated by MarcoModel 8.0

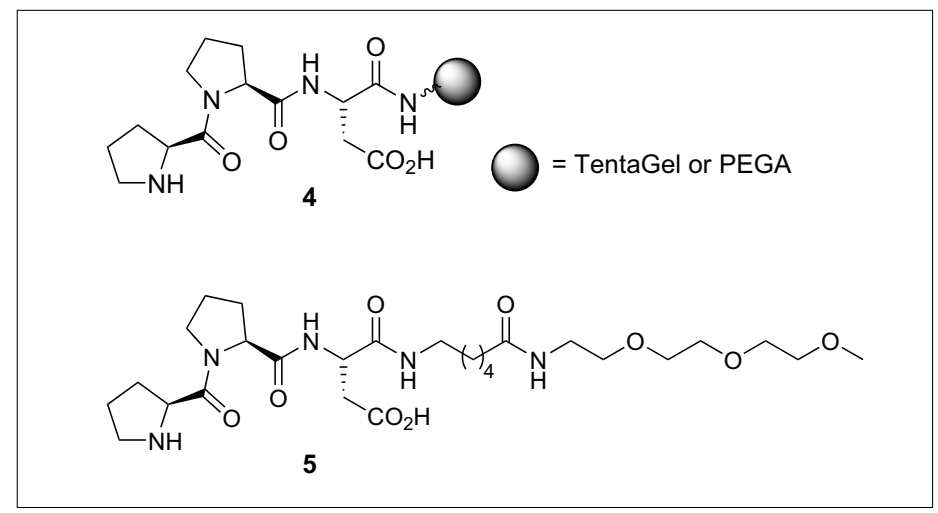

Fig. 4. Solid supported peptide $\mathbf{4}$ and peptide-PEG conjugate $\mathbf{5}$

antioselectivity of $\mathbf{1}$ and 2: An overlay of their lowest energy structures revealed that peptides $\mathbf{1}$ and $\mathbf{2}$ adopt turn conformations with opposite handedness. Thus, the righthanded turn of $\mathbf{1}$ and the left-handed turn of $\mathbf{2}$ are most likely responsible for their opposing enantioselectivity.

The versatility of particularly peptide 1 was further increased by immobilization on a solid support and functionalization with a triethylene glycol chain at the $\mathrm{C}$-terminus (Fig. 4).[11,12]

The immobilized peptide 4 possesses equally good reactivity and selectivity compared to $\mathbf{1}$ and allows for reusage for at least four times with the same good performance. Since the peptide was selected in the combinatorial screening when bound to a solid support the good performance of $\mathbf{4}$ is possibly not too surprising and suggests that the method of catalyst-substrate coimmobilization is a good tool for the development of solid-supported catalysts. The pegylated peptide $\mathbf{5}$ has a solubility that is significantly higher compared to that of $\mathbf{1}$. As a result, the catalyst loading can be further reduced to $0.5 \mathrm{~mol} \%$ when 5 is used to catalyse aldol reactions. ${ }^{[11]}$

\section{Conclusions}

H-Pro-Pro-Asp- $\mathrm{NH}_{2}$ and H-Pro-D-AlaD-Asp- $\mathrm{NH}_{2}$ have been developed as efficient catalysts for aldol reactions. Their activity is significantly higher compared to that of proline and other secondary amines, demonstrating that the higher complexity of peptidic catalysts can be a good trade-off for higher activity. Furthermore, peptidic catalysts proved attractive since the selectivity can be easily modified by simple changes in their structure through the use of different amino acids. The work demonstrated the value of the combinatorial screening method of 'catalyst-substrate coimmobilization' for catalyst discovery, a method we are currently using to investigate the optimal size of peptidic catalysts for aldol reactions and for the discovery of peptides for other reactions.

\section{Acknowledgements}

This work has been carried out by a group of dedicated coworkers. I am extremely grateful to them for their enthusiasm and ability. The work was generously supported by the Swiss National Science Foundation and by Bachem with an endowed professorship.

Received: April 2, 2007

[1] 'Modern Aldol Reactions', Ed. R. Mahrwald,Wiley-VCH, Weinheim, 2004, Vol. 1 and 2.

[2] For recent reviews see: a) M. S. Taylor, E. N. Jacobsen, Angew. Chem., Int. Ed. 2006, 45, 1520; b) M. J. Gaunt, C. Johansson, A. McNally, N. T. Vo, Drug Discovery Today 2006, 12, 8; c) B. List, Chem. Commun. 2006, 819; d) G. Guillena, D. J. Ramón,
Tetrahedron: Asymmetry 2006, 17, 1465; e) 'Asymmetric Organocatalysis', Eds. A. Berkessel, H. Gröger, Wiley-VCH, Weinheim, 2005.

[3] For recent reviews see: a) J. D. Revell, H. Wennemers, Curr. Opin. Chem. Biol. 2007, in press; b) S. J. Miller, Acc. Chem. Res. 2004, 37, 601; c) A. Berkessel, Curr. Opin. Chem. Biol. 2003, 7, 409; d) M. H. Fonseca, B. List, Curr. Opin. Chem. Biol. 2004, 8,319 . and references therein.

[4] a) H. J. Martin, B. List, Synlett 2003, 1901; b) J. Kofoed, J. Nielsen, J.-L. Reymond, Biorg. Med. Chem. Lett. 2003, 13, 2445; c) Z. Tang, Z.-H. Yang, L.-F. Cun, L.-Z. Gong, A.-Q. Mi, Y.-Z. Jiang, Org. Lett. 2004, 6, 2285; d) S. B. Tsogoeva, D. Wei, Tetrahedron Asymmetry 2005, 16, 1947; e) A. Córdova, W. Zou, P. Dziedzic, I. Ibrahem, E. Reyes, Y. Xu, Chem. Eur. J. 2006, 12, 5383.

[5] For a recent overview see: J. D. Revell, H. Wennemers, Top. Curr. Chem. 2007, in press, DOI 10.1007/128_2007_117 and references therein.

[6] P. Krattiger, C. McCarthy, A. Pfaltz, H. Wennemers, Angew. Chem., Int. Ed. 2003, 42, 1722 .

[7] P. Krattiger, R. Kovàsy, J. D. Revell, S. Ivan, H. Wennemers, Org. Lett. 2005, 7, 1101.

[8] a) Á. Furka, F. Sebestyén, M. Asgedom, G. Dibô, Int. J. Pept. Protein Res. 1991, 37, 487; b) K. S. Lam, S. E. Salmon, E. M. Hersh, V. J. Hruby, W.M. Kazmierski, R. J. Knapp, Nature 1991, 354, 82.

[9] P. Krattiger, R. Kovàsy, J. D. Revell, H. Wennemers, QSAR Comb. Sci. 2005, 24, 1158.

[10] J. D. Revell, P. Krattiger, H. Wennemers, unpublished results.

[11] J. D. Revell, D. Gantenbein, P. Krattiger, H. Wennemers, Biopolymers (Pept. Sci.) 2006, 84,105

[12] J. Grun, J. D. Revell, M. Conza, H. Wennemers, Bioorg. Med. Chem. 2006, 14, 6197. 